\title{
Maqdes A, Levy B, Klouche S, Hardy P. The feasibility and results of an arthroscopic removal of humeral locking plates and glenohumeral arthroylsis after proximal humeral fractures. Knee Surg Sports Traumatol Arthrosc 2013 Feb 9. [Epub ahead of print] Doi 10.1007/s00167-013-2437-8
}

\author{
Ali Maqdes $\cdot$ Bruno Levy $\cdot$ Shahnaz Klouche $\cdot$ \\ Philippe Hardy \\ Received: 19 July 2013/Accepted: 21 August 2013/Published online: 30 August 2013 \\ (C) Springer-Verlag Berlin Heidelberg 2013
}

Dear Editor,

We express a great deal of gratitude for Katthagen et al. for their comments regarding our publication "The feasibility and results of an arthroscopic removal of locking plates and glenohumeral arthrolysis after proximal humeral fractures" published in the journal in February 2013.

We acknowledge the presence of prior articles cited in our paper that describe the technique $[1,4]$ but have unfortunately not been able to find the article mentioned in the letter prior to our publication.

After a closer inspection, we have been able to retrieve the article written in German mentioned and review its content [2]. Effectively, our publication is therefore not the first to review results of this technique as mentioned in the original article. We apologize for this unintentional omission.

Nevertheless, all available studies [1-4] confirm the importance and benefit of this technique, in one way or the other, over the conventional open removal technique.

\section{References}

1. Dines JS, Hettrich CM, Kelly BT, Savoie FH 3rd, Lorich DG (2010) Arthroscopic removal of proximal humerus locking plates. Knee Surg Sports Traumatol Arthrosc 18(3):409-411

2. Katthagen JC, Jensen G, Hennecke D, Lill H, Voigt C (2012) Arthroscopic implant removal after fixed-angle plate osteosynthesis of the proximal humerus. Technique and initial results in comparison to open implant removal. Unfallchirurg 115(1):47-54

3. Maqdes A, Levy B, Klouche S, Hardy P (2013) The feasibility and results of an arthroscopic removal of humeral locking plates and glenohumeral arthrolysis after proximal humeral fractures. Knee Surg Sports Traumatol Arthrosc. doi:10.1007/s00167-013-2437-8

4. Voigt C, Geisler A, Lill H (2010) Arthroscopic locking plate removal after proximal humeral fractures. Arch Orthop Trauma Surg 130(3):391-395
A. Maqdes $(\varangle) \cdot$ B. Levy $\cdot$ S. Klouche $\cdot$ P. Hardy Hôpitaux Universitaires Paris Ile-de-France Ouest, AP-HP, 92100 Boulogne-Billancourt, France e-mail: ali.maqdes@gmail.com 